tion, and so double the width of the dark lines, but will produce no new ones; it will also reduce the brightness of the spectrum to its original state. Now, when we were dealing with sodium light, we at this stage of proceeding halved the width of the slit, for the images of the slit had been doubled without their brightness being reduced, so we could halve them and bring them to their original size, and so increase the distance of separation still more; but with a continuous spectrum, if we close the slit we shall, it is true, only decrease the width of each image of the slit and not their brightness, but we decrease their overlapping and so decrease the brilliancy of the whole spectrum, and this we cannot afford to do, as we have started with as narrow a slit as possible, and consequently with as small a brilliancy as possible consistent with showing the dark lines. We have therefore by this alteration of size of glasses doubled the width of dark lines originally visible, but we are not able to more than double the separation of any two images of the slit, as we did with the sodium light images, by narrowing the slit in addition to increasing the distance of the centres, and therefore no new lines are produced; in fact, the result of our change of arrangement has been the same as a simple magnification of the spectrum without a decrease in brilliancy; and an increase of prismatic power is exactly similar in effect, as we shall presently show, though it seems at first untrue that increase of prismatic power will not increase the number of dark lines visible. Let us now double the number of prisms; then the length of the spectrum will be doubled, and the distance of the centre of the images of the slit doubled, and therefore more dark lines may appear in addition to the original ones being widened, but the brilliancy of the spectrum has been halved, and in order to brighten the spectrum to the original state the width of the siit must be doubled, which exactly undoes all that the extra prisms have done in producing more lines; for the images will expand and obliterate the newlyformed lines; the original dark lines will, however, after the widening of the slit, be double their original width; so that, as we have just stated, the increase of prismatic power will not make a greater number of dark lines visible. If we illuminate the slit more intensely, we may decrease the width of the slit and still retain our original brightness, and so obtain a reduction in the width of the images, and consequently a greater separation between their edges, and therefore an increase in the number of dark lines in addition to increase of width of those originally visible; so that for the same kind of light the number of dark lines depends on the intensity of the illumination of the slit.

In dealing with the spectrum of an intense light like that of the sun, where there are a large number of lines, it is necessary to use an instrument of high power, whether in number or size of prisms, in order that the exceedingly fine dark lines produced by a low power may be, as it were, magnified without loss of light, which is, as we have shown, the effect of an increase of prismatic power; and in order that these fine lines may become visible and sufficiently separated to render their identity for measurement or otherwise complete, so there may be an apparent increase in the number of lines by the invisible ones being rendered visible by magnification without loss of brilliancy in the spectrum.

But in dealing with light like that from a planet or the moon, where the slit must be so wide that few lines are visible, it can soon be tested in practice that the increase of power does not increase the number of lines. In examining the light of the moon or of a nebula, or any object having an appreciable diameter, any increase of telescopic power for the purpose of forming the image on the slit will not increase the useful brightness of the slit; for, supposing a spectroscope be working to its greatest advantage on a telescope, then, if the diameter of the object-glass of the telescope be doubled, the angle it subtends at the slit will be doubled, and the cone of rays on the collimator side of the slit will have its base doubled, and therefore it cannot all pass through the collimating lens; in fact, all the rays newly added by the increase of diameter of object-glass will be wasted against the tube of the collimator, and if we try to utilise these rays by increasing the size of collimating lens or decreasing its focal length, we shall also have to increase the power of the eyepiece to get all the rays into the eye, and so reduce the brilliancy of the spectrum to its original state. In the case of increasing the focal length of a telescope as well as its aperture, the brightness of the image on the slit is not increased, but only its size; so the spectroscope is unaffected. But in the case of viewing the spectrum of a star, matters are altered, for the image of the star does not increase in size by increasing the focal length of the telescope together with its apertures; but its brilliancy is increased, and therefore greater prismatic power can be used without increase of width of slit, and more dark lines seen; so that for stellar spectroscopy an increase of telescopic apertures is a direct advantage. From the foregoing remariss we gain that in the construction of a spectroscope the eyepiece should be of as long a focus as possible, so as just to cause all the rays to enter the eye; all magnification beyond this means loss of brilliancy, and if the spectrum appea is insufficiently large an increase in size of the collimatin $\mathrm{g}$ and telescope lenses, together with the prisms, or an increase in the number of the prisms should bo nade, until the spectrum appears sufficiently larse to suit the requirements of the observer.

G. II. S.

\section{THE SUB-WEALDEN EXFLORATLON}

THE Secretary of the Sub-Wealden Exploration has just issued his eighth quarterly report, in which he states that but little progress has been made during the last three months in consequence of the inability to procure lining tubes of the required size in sufficient quantity. The increased favour in which the diamond boring system is now held has caused a great demand for these tubes, and they are specially manufactured by an eminent Birmingham firm. The new pipes are required for the difficult process of enlarging and lining the bore-hole to the diameter considered recuisite before attempting to withdraw the broken rods, \&ce. Mr. Willett says:-

"The engineers have no doubt whatever of their ultimate success, and as the extraction of the rods is not a matter involving the expenditure of oux funds, we can only regret the loss of the long summer days, and take comfort from the assurance that, "after the enlargement and lining is accomplished, there is a much better prospect of obtaining the desired depth of 2,000 ft. than there was a year ago that we should reach half the distance $(1,000 \mathrm{ft}$.$) ,$ provided always that the requisite funds be forthcomizig:'"

He is anxious to dispel what he terms "the delusion" that no more money is required from the public in consequence of a Government grant to the work having been obtained. He states that the Chancellor of the Exchequer, with laudable foresight and prudence, has promised to assist on certain conditions, to do which-

"I. We must spend 400 . in boring tubes, \&c.

II. We must bore $100 \mathrm{ft}$, which will cost $200 \%$; and then, and not till then,

III. We can draw 100 . from the Exchequer, and so on, claiming $100 \%$. for every roo ft. actually explored."

The third and last year of the tenancy for carrying out the work has been entered on, and therefore the necessity of speedily resuming the operations is at once seen. The financial position is cheering, the present balance being 594l. $7 s, 9 \%$. The honorary secretary says :-

"We are greatly indebted to the Right Hon, the Chan- 
cellor of the Exchequer, and to the Secretary of the Treasury (by whom the deputation was introduced), for having favoured us with an interview and patiently listened to our appeal for Government aid.

"The grounds of our claim were stated in our last report, and were naturally met by the remark that 'it would be a dangerous precedent to apply national funds for private purposes.' If all future applicants be compelled to

I. Raise 3,000 l. by subscription ;

II. Bore I,000 feet; and

III. Obtain a memorial from the Royal Society, the Geological Society, and the Institute of Civil Engineers, stating that the prosecution of the work is of national importance ;

they are not likely to be troublesome by their numbers, and the subject having been ventilated in the House of Commons, few reasonable minds will be disposed to doubt the discretionary wisdom of the grant with its attendant conditions.

"We are much indebted to William Topley, Esq., F.G.S., for having consented to visit Belfast, there to read our report and make personal application for additional aid from the Committee of Recommendation of the British Association for the Advancement of Science, and we are greatly encouraged by the response and the grant of $100 l$.

"The kind promise of Sir Charles Blunt to give us 50 . on reaching $\mathrm{I}, 000 \mathrm{ft}$. has been faithfully performed; so also will Mr. Warner's promise of $300 \%$. when we reach $2,000 \mathrm{ft}$.

"In scientific research it has often occurred that the benefits accruing have been indirect and unexpected by the promoters. Not only have the rich beds of gypsum been made known, and, in consequence, are now in actual process of development, but the new facts ascertained by our work have thrown some considerable light (and that of an encouraging nature) on the problem of the feasibility of constructing a sub-marine tunnel between England and France.

"The motives which actuate our friends to subscribe are various and sometimes novel, as, for instance, one writes : "I enclose my mite-besides the objects stated, a shaft is doubtless a safety valve against earthquakes.'"

The report concludes by thanking the directors of the London, Brighton, and South Coast, and the South Eastern Railways, for their assistance in the work, the latter company having, in addition to granting other privileges, in the use of their line, forwarded a cheque for $50 l$. The kindness of the Earl of Ashburnham, the Rev. $\Gamma$. Partington, and many others is acknowledged, and the honorary secretary concludes his report with an earnest hope for further encouragement, and that the results will prove that their labour has not been expended in vain.

\section{NOTES}

THE inhabitants of a vast district of London have had during the past week an opportunity of studying the phenomena of explosions on a large scale, and of noticing how closely they approach those of earthquakes in the sequence of long-rolling waves of the solid earth, loud noises, and finally long continued tremulous motion and more subdued sounds. If we could have announce 1 last week that roo barrels of gunpowder would explode in London, locality not defined, on a given day, the inhabitants would probably have been alarmed, many would certainly have visited their country $f_{i}$ iends ; but our Government have for years been warned that such an occurrence might happen seeing that there is no legislative enactment to ensure care, and yet they have let such a state of things continuc! We have it on the authority of the Times that the Tiluury might have had 500 barrels on board instead of 100 , and it is clear that these might have exploded in a locality where the consequent destruction of life and property would be fearful to contemplate. It appears that, bad as are the regulations for the transport of gunpowder on board ship, there is little or no provision for the prevention of accidents at places where powder is received and delivered in large quantities. In reporting on this branch of the subject in 1865, Major-General Boxer instanced the case of Isleworth. He says :- "The powder wharf at Isleworth affords a good illustration. This wharf is situated in the town of Isleworth, on the banks of the Thames; on an average as much as 600 barrels per week is shipped there, the wharf is surrounded by houses, and the sacrifice of life would be fearful in the event of an explosion." Major Majendie, in a report to Government two years ago, wrote :- "I am quite sure that if the public were at all aware of the extent to which gunpowder is handled in large quantities, without any special regulations, in the middle of the metropolis and of large cities, they would be seriously alarmed, and would demand the adoption of measures for removing so patent a danger." Truly we are a practical people, and much superior to the Germans, who only allow the transit of large quantities of gunpowder through populous districts under military escort.

THE effect of the explosion in the Zoological Gardens was not so serious as might have been expected from the proximity of the gardens to the scene of the disaster, but several of the animals were thrown into a state of great agitation. The elands, antelopes, and deer, particularly, were very much startled, and were found ruming round their enclosures in a $\mathrm{s}$ ate of great alarm. The elephant, hippopotamus and rhinoceros, and the giraffes were very much excited, and the birds became much alarmed. About a dozen of the smaller birds escaped through a hole in the glass roofs of the aviary, caused by the concussion, but two or three returned during the day. The blankets and coverings were shaken off the snakes, but fortunately none of the glass in their cages was fractured. It was fortunate, too, that none of the large carnivora were'liberated.

WE referred some little time ago to the fact that a sum of about $30,000 l$. had been left to the "London Academy of Sciences." We hear that already several societies and institutions have sent in, or are thinking of sending in, claims. It is stated, however, that the Royal Society, which certainly is the nearest approach to the institution in Signor Ponti's mind, has not applied. The Royal Society is of course a mere private body, and might well be held to he justified in refusing to incur the responsibility of distributing a large sum for the furtherance of science; but the miserable chaos in our scientific arrangements is none the less strongly brought out by the present juncture. In Lngland, truly, Science is a body without a head!

FRANCE, Germany, and Austria are vying with each other in astronomical activity. In the grounds of the Paris Observatory a $4 \cdot \mathrm{fc}$. Foucault mirror is being erected, and M. Le Verrier has already obtained a grant for a 30-in. refractor. The Vienna Observatory is also making arrangements for the reception of a telescope of similar aperture. Messrs. Merz have nearly completed a lens of 20 in. aperture, for the University of Strassburg. In France, the newly-created Ecole Speciale des Hautes Etudes is being taken alvantage of to form a school of Astronomy; in Germany and America many such schools exist already, thanks to the rational administration of their Observatories, the assistants in which are the pupils, friends, and potential successors of the director.

M. Desjardins, one of the head officials in the Ministry of Public Instruction, has been ordered by the Minister to inspect the meteorological service of the Observatery and to report upon its present condition.

THE Government of Newfoundland has determined to take steps for the protection of the seal fisheries, by prcventing vessels 